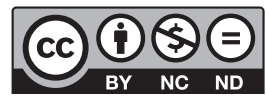

Estudos Teológicos foi licenciado com uma Licença Creative Commons Atribuição - NãoComercial - SemDerivados 3.0 Não Adaptada

\title{
EDITORIAL
}

\section{Quem e o que se perde no contexto da pandemia da Covid-19}

No crepúsculo do ano de 2019, a China foi surpreendida com o aparecimento de uma nova configuração do coronavírus, que ganhou o nome de Sars-Cov-2, altamente contagioso e causador de uma doença letal, a Covid-19. Não tardaria para o mundo conhecer de perto os efeitos desastrosos dessa enfermidade que, em poucos meses, espalhou-se por todos os continentes, tornando-se um desafio, à primeira vista, intransponível pelas economias e pelos governos contemporâneos.

Diferentemente das guerras e das crises econômicas, pandemias virais ou bacterianas não respeitam fronteiras e colocam em xeque as estruturas mais consolidadas dos sistemas gerenciais, em todos os âmbitos da vida social. Pandemias golpeiam, frontalmente, o coração da modernidade: a convicção de que não só devemos, mas de que podemos, de fato, controlar tudo aquilo que consideramos ser o nosso mundo. E nada escapa do que imaginamos ser de nossa pertença, afinal, concebemos que tudo é nosso: temos o nosso próprio corpo, a nossa própria consciência, o nosso próprio trabalho, a nossa própria economia, o nosso próprio governo, a nossa própria ciência, a nossa própria religião, o nosso próprio Deus - ou deuses -, a nossa própria cultura, o nosso próprio ambiente, a nossa própria comunidade, enfim, tudo é, ou está, sob o nosso domínio, ao mesmo tempo em que nos identificamos com tudo o que pensamos ser nosso.

No esforço de controlar o universo, naturalizamos nossa forma de viver, não nos dando conta da artificialidade implicada em todo esse movimento que fazemos. E, nessa trama, costumamos nos esquecer do ímpeto de fuga do medo que temos da morte, provavelmente o mais primevo de todos os medos que sentimos, ainda que de modo inconsciente.

Pandemias colocam a nu este elemento fundamental do qual nos esquivamos, o medo de morrer, e como estamos tão habituados a construir mundos - e a nos apropriar deles -, passamos, imediatamente, quando nos damos conta do perigo real da morte, a dar toda a carga às estruturas de controle por nós criadas, às quais nos apegamos e, consequentemente, nos submetemos. Nesse momento, dois pilares, em princípio antagônicos entre si, nossas ciências e nossas religiões, ganham força, e nelas depositamos nossas expectativas, esperando que possam nos salvar.

Pari passu a essa busca afirmativa por soluções que possam garantir a nossa vida, seja pela ciência que nos resguardará com a descoberta de uma vacina eficaz, seja pela religião, por meio da qual garantimos legitimidade à nossa fé no Deus que, de qualquer modo, nos protegerá, podemos observar, por outro lado, um movimento 
negacionista, vocalizado e dirigido por representantes do grande mercado, cujo fim é sempre o lucro, custe o que custar. Mas é possível também pensar, em um prisma psicanalítico, que tal negacionismo resulta de provável reação das pessoas que mais se beneficiam das economias de mercado, ao medo de encarar o pior dos medos: o da própria morte.

Todas essas ações, se não estamos enganados em nossa hipótese, se erguem, todavia, sobre as mesmas bases: a de luta pela vida por oposição à constatação da morte, a de busca pelo controle do mundo lastreada na percepção de que apenas somos e estamos porque fazemos as coisas pertencerem a nós, ao mesmo tempo em que pertencemos a elas.

A partir dessas breves considerações, perguntamo-nos: quem e o que se perde no contexto da pandemia da Covid-19?

Em resgate a duas obras de maior densidade, Communitas: origem e destino da comunidade, e Immunitas: proteção e negação da vida, Roberto Esposito publicou, em 25 de maio de 2020, pequeno texto intitulado $O$ que realmente significa a palavra "imunidade". Aqui, o filósofo contemporâneo reflete sobre o discurso da imunidade, cuja amplitude extrapola, em muito, os limites da política sanitária. Escreve:

[...] se prestarmos atenção à etimologia latina da palavra, perceberemos que immunitas é o contrário de communitas. Ambos derivam do termo munus, que significa ofício, obrigação, dom para com os outros. Mas enquanto os membros da communitas estão unidos por esse vínculo de doação mútua, quem é imune é exonerado da mesma. E, portanto, protegido do risco que toda relação social comporta em relação à identidade pessoal ${ }^{1}$.

Esposito salienta que, com o advento da cristandade, a associação do termo latino communitas com a expressão neotestamentária koinonia - comunhão entre as pessoas e com Deus - conduziu à acepção de pertença e, como decorrência de uma simplificação jurídica de tal concepção ocorrida na Idade Média, à ideia de propriedade de si, que cada comunidade passa a ter a partir de sua institucionalização jurídico-política. Tal associação - de comunidade com propriedade - não se apagará desde a criação dos burgos até a contemporaneidade, embora o termo comunidade ganhe, ao longo da história, novos contornos, como no caso de um neocomunitarismo em reação ao individualismo que a modernidade viu nascer. ${ }^{2}$

É ao significado de communitas enquanto doação, gratuidade, e não de privação - ou propriedade, exclusividade -, porém, que damos preferência aqui. Esposito atenta para a dubiedade da operação teológica que atrela a cristandade a Jesus Cristo. Se, por um lado, a humanidade, pelo sacrifício de Cristo, recebe o dom da gratuidade, por outro, atrela-se a ele por seu sofrimento, não participando da glória que a ressurreição oferta,

1 ESPOSITO, Roberto. O que realmente significa a palavra "imunidade". IHU Unisinos, São Leopoldo, 25 de maio de 2020. Disponível em: <http://www.ihu.unisinos.br/78-noticias/599287-o-que-realmentesignifica-a-palavra-imunidade>. Acesso em: 04 out. 2020.

2 Cf. ESPOSITO, Roberto. Communitas: origen y destino de la comunidad. Buenos Aires: Amorrortu, 2003. 
mas do drama do sangue derramado na cruz. ${ }^{3}$ Consideramos, todavia, que se deve levar a sério o entendimento de comunidade no sentido libertário daquele que renasce, ao invés de acentuar-se o pecado que o arquétipo do sofrimento pode reclamar.

A liberdade comunitária enseja, por sua vez, uma releitura de seu significado original. Aqui, o ofício, o serviço e o dom abrem-se para a responsabilidade e o cuida$d o$ - consigo mesmo e com o outro. Nesse sentido, como bem observa Esposito ${ }^{4}$, qualquer corpo individual ou corpo social não pode sobreviver por muito tempo isento de um sistema imunitário. O filósofo chama a atenção, no entanto, para que tal fórmula não deve extrapolar, todavia, a razoabilidade, sob pena do surgimento de "danos irreparáveis", não somente na esfera econômica, mas, também, o que é seguramente mais preocupante, no plano antropológico. Viver no éthos imunitário é não comprometer-se com a mútua doação, é não responsabilizar-se pela extensão de seus atos e, por fim, não empenhar-se no cuidado de si e, tampouco, do outro.

Perder-se de si mesmo, perder o outro, perder-se do outro é o grande problema que se coloca desde o advento do empossamento da res (coisa pública) e de sua consequente apropriação. ${ }^{5}$ Mas, em toda a história humana, certamente nunca se experienciou o distanciamento entre sujeito e comunidade com tamanha força. $\mathrm{O}$ alto

3 "Sabemos que al menos a partir de Act., 2,42 — pero sobre todo a partir de la entera primera ¡epístola paulina a los Corintios_- y a lo largo de la totalidad de la literatura patrística, el «lugar común» de la koinonia lo constituye la participación eucarística en el Corpus Christi representado por la Iglesia. Pero el problema que se plantea reside justamente en estas dos figuras vinculadas, y sin embargo distintas: la «representación» y la «participación». En cuanto a esta última noción, los comentaristas más atentos siempre señalaron que se debe tener presente la dimensión vertical ${ }^{27}$ que establece la unión —y a la vez la separación, por la infinita heterogeneidad de sustancia - de hombre y Dios. O mejor, Dios y hombre, dado que sólo al primero corresponde la subjetividad - la iniciativa - del vínculo, respecto del cual* el segundo sólo puede tener una actitud receptiva. El recibe el don —y aquí reaparece el munus—que Dios, mediante el sacrificio de Cristo, le hace de manera v gratuita y sobreabundante' (Jn., 3,16; Jn., 7,37-38). En contra de una lectura antropológica chata — exclusivamente horizontal — de la «participación», debemos recalcar con firmeza que sólo ese primer muñus desde lo alto acomuna a los hombres. Precisamente este «dado» — lo que nos es dado: nosotros mismos como «dados», «donados», «nacidos del don»— impide cualquier apresurada traducción de la koinonia como simplephilia — «amistad», «fellowship», «camaraderie», «Freundschaft»—. Somos hermanos, koirionoi, pero en Cristo, es decir, en una alteridad que nos sustrae nuestra subjetividad, nuestra propiedad subjetiva, para clavarla al punto «vacío de sujeto» del qüe venimos y hacia el que se nos llama. Siempre que tengamos tanta «gratitud» como para retribuir a ese primer munus con un don en correspondencia. Ello no impide, sin embargo, que nuestro donar sea inevitablemente inadecuado, defectivo, puramente reactivo en comparación con el único don verdadero, en tanto incondicionado, que ya hemos recibido del Donador (Ia Cor., 1,9; 2a Cor., 9,15). Pero entonces debemos deducir que el que efectuamos no es un verdadero don, o que no es enteramente nuestro (Ia Cor., 4,7). Que la posibilidad del don nos es sustraída en el mismo momento en que nos es dada; o bien que nos es dada en la forma de su sustracción. Esta inflexión donativa de la «participación» devuelve a la koinonia cristiana todo el dramatismo expropiativo del antiguo munus: no se participa de la gloria del Resucitado, sino del sufrimiento y la sangre de la Cruz (Ia Cor., 10,16; Fil., 3,10). Se pierde cualquier posibilidad de apropiación: «tomar parte» significa todo menos «tomar»; por el contrario, es perder algo, reducirse, compartir la suerte del siervo, no la del, señor (Fil., 3, 10-11). Su muerte. El don de la vida, ofrecida en el arquetipo comunitario de la Cena." (ESPOSITO, 2003, p. 36, 37.)

4 ESPOSITO, 2020.

5 Sobre o nascimento da posse e da propriedade por oposição ao originário conceito de coisa pública, veja-se ESPOSITO, Roberto. As pessoas e as coisas. São Paulo: Editor Rafael Zamperetti Copetti, 2016. 
desenvolvimento tecnológico, de dimensões globais, não poupa nenhuma sociedade contemporânea nele enredada do afastamento social. A modernidade já inaugurava a submissão do corpo à máquina. Todavia, a dependência da força de trabalho humano impunha, ainda, no processo de produção, determinados limites ao império da máquina. A revolução tecnológica pela qual passamos, na contemporaneidade, todavia, impõe a mais absoluta coisificação do ser humano. Os equipamentos não são mais instrumentos de trabalho. Contrariamente, somos agora, nós mesmos, as ferramentas da tecnologia, guiados por seus dispositivos de controle. ${ }^{6}$ Nesse solo tão árido para a convivência comunitária, em que o termo comunidade virtual, na qual perfis na internet substituem com a maior naturalidade as pessoas, a pandemia parece evidenciar, ou, mais do que isso, potencializar mesmo o afastamento, de cariz imunitário, entre as pessoas. Realçamos a seguinte reflexão de Esposito:

A globalização, a imigração, o terrorismo - eventos muito diferentes entre si - potencializam ao máximo a ansiedade da imunização das sociedades contemporâneas, modificando nossos comportamentos desde a raiz. Basta pensar, para mencionar outro âmbito, nos enormes e muitas vezes inúteis esforços para proteger os sistemas informáticos dos vírus que os ameaçam. Ou mesmo nas companhias de seguros, que sempre trabalharam sobre a imunização do risco. Naturalmente, a pandemia leva essa necessidade imunitária ao extremo, tornando-a o epicentro real e simbólico de nossa experiência.

Nunca como hoje - sob o ataque do coronavírus - o paradigma imunitário se tornou a pedra angular do sistema, o pivô em torno do qual parece girar toda a existência. De qualquer lado - biológico, social, político - se questione a nossa vida, o imperativo permanece o mesmo: prevenir o contágio onde quer que esteja. Claro que se trata de uma exigência real.

$[\ldots]$

A imunidade é uma proteção, mas uma proteção negativa - que nos afasta do mal maior através de um mal menor. A própria vacinação - esperamos que chegue o mais rápido possível - protege introduzindo em nosso corpo um fragmento, controlado e tolerável, do mal do qual queremos nos defender. Aliás, o termo grego "fármaco" significa remédio e veneno ao mesmo tempo. Isso também vale para o plano social. Tudo se resume em respeitar as proporções - o delicado equilíbrio entre comunidade e imunidade. $\mathrm{O}$ fe-

6 Em certo ponto da arqueologia que realiza sobre o corpo, o pensador hodierno Giorgio Agamben afirma: "[...] é necessário restituir ao escravo o significado decisivo que lhe cabe no processo da antropogênese. O escravo é, por um lado, um animal humano (ou um homem-animal) e, por outro, e na mesma medida, um instrumento vivo (ou um homem-instrumento). Assim, o escravo constitui, na história da antropogênese, um limiar duplo: nela, a vida animal transpassa para a humana, assim como o vivo (o homem) transpassa para o inorgânico (instrumento), e vice-versa. A invenção da escravidão como instituto jurídico permitiu a captura do ser vivo e do uso do corpo nos sistemas produtivos, bloqueando temporariamente o desenvolvimento do instrumento tecnológico; sua abolição na modernidade libertou a possibilidade da técnica, ou seja, do instrumento vivo. Ao mesmo tempo, enquanto sua relação com a natureza não é mais medida por outro homem, mas por um dispositivo, o homem afastou-se do animal e do orgânico para se aproximar do instrumento e do inorgânico até quase identificar-se com ele (homem-máquina). Por isso - enquanto havia perdido, com o uso dos corpos, a relação imediata com a própria animalidade -, o homem moderno não pôde apropriar-se realmente da libertação com relação ao trabalho que as máquinas deveriam ter-lhe proporcionado. E, se a hipótese de um nexo constitutivo entre escravidão e técnica for correta, não causa espanto que a hipertrofia dos dispositivos tecnológicos tenha produzido uma nova e inaudita forma de escravidão" (AGAMBEN, Giorgio. O uso dos corpos. São Paulo: Boitempo, 2017. (Homo Sacer, IV, 2). p. 102. 
chamento é necessário. Mas até o ponto em que a negação não prevaleça sobre a proteção, minando o mesmo corpo que deveria defender. É o que acontece nas doenças autoimunes, quando o sistema imunológico cresce a ponto de se autodestruir. Cuidado - esse limiar pode não estar longe. Hoje, sob a pressão do vírus, a única maneira de as nossas sociedades se salvarem passa pela dessocialização. E também pelo sacrifício de algumas liberdades pessoais. Mas até quando isso será possível sem perder o significado mais intenso de nossa existência, que é a vida de relação? A mesma imunidade que serve para salvar a vida poderia esvaziá-la de sentido, sacrificando à sobrevivência toda forma de vida. ${ }^{7}$

A pandemia, enquanto fenômeno datado, pode ser superada. Mas a vida fundada na imunidade veio para ficar, caso não tomemos consciência sobre sua presença e os efeitos devastadores que ela gera.

Uma compreensão atual sobre o múnus passa, necessariamente, por reflexão séria e acurada a respeito na natureza e, com ela, da alteridade - da nossa existência originária e prioritariamente natural. Nesse sentido, não é mais possível esperar por uma consciência ecológica. Ou desempenhamos, agora, um novo modelo de vida, centrado na mais profunda relação de respeito e integração com todos os entes e elementos da natureza, ou criamos efetivamente as condições para a prevalência de uma cultura de paz - em que quaisquer ímpetos de apego, de voracidade, de aversão ou de indiferença não resistam à prática do amor, da doação -, ou nos tornaremos, cada vez mais, reféns dos efeitos do desequilíbrio sistêmico que insistimos em provocar.

Fundamentado em biólogos como Rob Wallace ${ }^{8}$, o Coletivo Chuang reuniu uma série de textos em um livro, publicando-o em diversas línguas. No Brasil, seu título foi traduzido por Contágio Social: Coronavirus e a luta de classes microbiológica na China. Destacamos, aqui, um de seus trechos que consideramos fazer boa síntese de sua tese-denúncia:

O vírus por trás da epidemia atual (SARS-CoV-2) foi, como o antecessor de 2003 SARS-CoV, bem como a gripe aviária e gripe suína antes dele, gestado no nexo entre a economia e a epidemiologia. Não é por acaso que muitos desses vírus assumiram o nome de animais: a disseminação de novas doenças para a população humana acontece através da chamada transferência zoonótica, que é uma maneira técnica de dizer que essas infecções saltam dos animais para os humanos. Esse salto de uma espécie para outra é condicionado por questões como proximidade e regularidade do contato, que constroem o ambiente em que a doença é forçada a evoluir. Quando essa interface

\footnotetext{
ESPOSITO, 2020.

No site da Elefante Editora, encontram-se as seguintes informações sobre Rob Wallace: “é biólogo evolucionista com PhD na Universidade da Cidade de Nova York e pós-doutor na Universidade da Califórnia. Foi consultor da Organização das Nações Unidas para Alimentação e Agricultura (FAO) e do Centro de Controle e Prevenção de Doenças Infecciosas (CDC) dos Estados Unidos, antes de ser ostracizado pelo status quo político e acadêmico devido a suas críticas à maneira como governos e organismos internacionais conduziam o combate aos novos vírus - ou seja, sem modificar o modo como vivemos e produzimos alimentos. Após o surto do novo coronavírus, no início de 2020, viu seus repetidos alertas se concretizarem, tornando-se uma das vozes mais respeitadas no assunto" (In: < https:// www.editoraelefante.com.br/autores/rob-wallace/>. Acesso em: 07 out. 2020).
} 
entre humanos e animais muda, também mudam as condições nas quais essas doenças evoluem. Para além das quatro fornalhas ${ }^{9}$, então, encontra-se uma fornalha mais fundamental subjacente aos centros industriais do mundo: a panela de pressão evolutiva criada pela agricultura e urbanização capitalistas. Isso fornece o meio ideal através do qual pragas cada vez mais devastadoras nascem, transformam-se, são induzidas a saltos zoonóticos e, em seguida, agressivamente vetorizadas através da população humana. A isso se somam processos igualmente intensivos que ocorrem nas margens da economia, onde cepas "selvagens" são encontradas por pessoas pressionadas a incursões agroeconômicas cada vez mais extensivas sobre os ecossistemas locais. O coronavírus mais recente, em suas origens "selvagens" e sua súbita disseminação por um núcleo fortemente industrializado e urbanizado da economia global, representa as duas dimensões da nossa nova era de pragas político-econômicas ${ }^{10}$.

Desativar os gigantescos aparatos de destruição de toda a natureza e de opressão aos seres humanos é tarefa que exige profunda disposição pela vida - de si, do outro e de todo o planeta. Nesse sentido, importante lembrar a encíclica assinada pelo papa Francisco, em 2015, a Laudato Si, na qual, além de denunciar o modelo econômico atual, baseado no consumismo, na exploração da natureza e das pessoas pobres, propõe também a necessidade urgente de uma nova economia mundial para o enfrentamento da degradação ambiental e das alterações climáticas. O modelo proposto pelo papa Francisco fundamenta-se numa economia do cuidado responsável e amoroso com a Casa Comum. O chamado é para todos os governos e também para todas as pessoas, se não assumirmos uma mudança em nossa forma de viver, novos vírus, certamente, irão surgir. Já há muito tempo nos alertava Dom Pedro Casaldáliga sobre a necessidade de romper com todas as cercas que nos privam de viver e amar.

Neste volume especial da revista Estudos Teológicos, dedicado ao tema "Teologia, Ciências das Religiões e a pandemia da Covid-19", lembramos o quão urgente é recuperarmos a noção de comunidade, de coisa realmente pública, o que inclui nossa fundamental ligação com a natureza. Rememorando o saudoso bispo emérito da Prelazia de São Félix do Araguaia, podemos com ele maldizer tudo o que nos priva de viver e de amar, todo sistema de barbárie que busca "fazer a Terra, escrava e escravos os humanos!" 11 e bendizer o que pode nos trazer de volta a nós mesmos, o que faz brotar em nós o anseio por uma "humana Terra livre", na qual podemos viver na graça e não mais no controle.

\section{Referências}

AGAMBEN, Giorgio. O uso dos corpos. São Paulo: Boitempo, 2017. (Homo Sacer, IV, 2). CASALDÁliGA, Pedro. Antologia retirante. Rio de Janeiro: Civilização Brasileira, 1978.

9 Referência às cidades (de clima bastante úmido) de Wuhan, Chongqing, Nanjing "e, alternadamente, Nanchang ou Changsha, todas agitadas e antigas, localizadas perto ou ao longo do vale do rio Yangtzé". COLETIVO CHUANG. Contágio social: Coronavírus e a luta de classes microbiológica na China. Tradução e apresentação de Amauri Gonzo. São Paulo: Veneta, 2020. (Coleção Baderna). E-book, p. 15.

${ }^{10}$ COLETIVO CHUANG, 2020, p. 23, 24.

${ }^{11}$ CASAldÁligA, Pedro. Antologia retirante. Rio de Janeiro: Civilização Brasileira, 1978. p. 193. 
COLETIVO CHUANG. Contágio social: Coronavírus e a luta de classes microbiológica na China. Tradução e apresentação de Amauri Gonzo. São Paulo: Veneta, 2020.

ESPOSITO, Roberto. Communitas: origen y destino de la comunidad. Buenos Aires: Amorrortu, 2003.

. As pessoas e as coisas. São Paulo: Editor Rafael Zamperetti Copetti, 2016.

. O que realmente significa a palavra "imunidade". IHU Unisinos, São Leopoldo, 25 de maio de 2020. Disponível em: <http://www.ihu.unisinos.br/78-noticias/599287-o-que-realmentesignifica-a-palavra-imunidade>. Acesso em: 04 out. 2020.

\author{
Glauco Barsalini \\ Claudete Beise Ulrich \\ Wilhelm Wachholz \\ Pela organização do Dossiê \\ Júlio Cézar Adam \\ Marcelo Ramos Saldanha \\ Pela organização geral da edição
}

